\title{
Brush Device
}

National Cancer Institute

\section{Source}

National Cancer Institute. Brush Device. NCI Thesaurus. Code C49851.

Device consisting of hairs or bristles set into a handle or holder, especially one that

conducts current between the rotating and stationary parts of a generator or motor. 